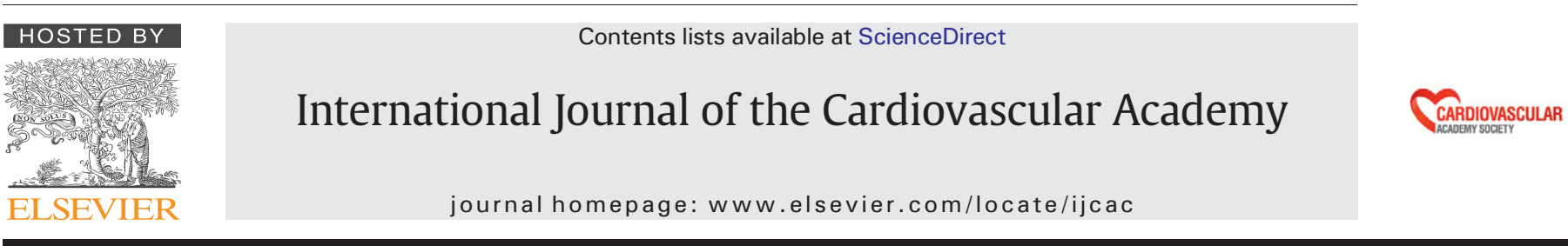

Short communication

\title{
Chemotherapy related myocardial infarction in a young patient with yolk
} \section{sac tumor}

\author{
Hayri Alici ${ }^{\mathrm{a}, *}$, Fethi Yavuz ${ }^{\mathrm{b}}$, Suleyman Ercan ${ }^{\mathrm{c}}$, Vedat Davutoglu ${ }^{\mathrm{c}}$ \\ a Department of Cardiology, 25 Aralik State Hospital, Gaziantep, Turkey \\ b Department of Cardiology, Dr. Ersin Arslan State Hospital, Gaziantep, Turkey \\ c Department of Cardiology, Gaziantep University, Gaziantep, Turkey
}

\section{A R T I C L E I N F O}

\section{Article history:}

Received 9 May 2015

Received in revised form 8 July 2015

Accepted 10 July 2015

Available online 11 September 2015

\section{Keywords:}

Myocardial infarction

Chemotherapy

Yolk sac tumor

\begin{abstract}
A B S T R A C T
Chemotherapy related myocardial infarction is rare but can be life-threatening. Herein, we present a 24-year-old yolk-sac tumor patient admitted to the emergency department with acute myocardial infarction. The patient had received the third cycle of combined chemotherapy with bleomycin, etoposide and cisplatin for days ago. Electrocardiogram showed acute anterior myocardial infarction and the patient was treated successfully with tissue plasminogen activator. To the best of our knowledge, this is the first case which was treated with fibrinolytic therapy in a patient with chemotherapy related myocardial infarction in literature. Cancer chemotherapy may be complicated by acute coronary events and physicians should assess cautiously patients according to their coronary symptoms and risk factors before and during chemotherapy.

(c) 2015 The Society of Cardiovascular Academy. Production and hosting by Elsevier B.V. All rights reserved. This is an open access article under the CC BY-NC-ND license (http://creativecommons.org/licenses/by-nc-nd/4.0/).
\end{abstract}

\section{Introduction}

Testicular cancer is one of the most common solid tumors in young adults. However, yolk-sac tumor (YST) is rare in this population. ${ }^{1}$ The mainstay therapy of YST is combined chemotherapy with cisplatin, etoposide and bleomycin (BEP) after testicular surgery. The main side effects of the chemotherapy regimen are renal dysfunction, peripheral neuropathy, pulmonary fibrosis, infertility, secondary leukemia and vascular toxicity. ${ }^{2}$ Vascular toxicity is usually venous, however arterial or coronary events due to chemotherapy are seen rare. Herein, we present a young patient with myocardial infarction (MI) during BEP chemotherapy for YST.

\section{Case Report}

A 24-year-old male patient was admitted to the urology clinic with pain and swelling in the right testicle. Right orchiectomy was performed on patients upon detection of mass lesion. The pathology report showed a nonseminomatous germ cell tumor (yolk sac tumor subgroup) and four courses of combined chemotherapy with BEP were planned. The patient received chemotherapy every twenty-one days in the doses of $100 \mathrm{mg} / \mathrm{m}^{2}$ cisplatin and $100 \mathrm{mg} / \mathrm{m}^{2}$ etoposide on the first 5 days and $30 \mathrm{mg}$ bleomycin on days 1,8 , and 15 of each course.

On the fourth day of the third chemotherapy course, the patient was admitted to the emergency department with severe chest pain. There

\footnotetext{
* Corresponding author at: 25 Aralik State Hospital, Department of Cardiology, 27310 Gaziantep, Turkey. Tel.: + 90532 6229242; fax: + 903423603928.

E-mail address: mhayrialici@hotmail.com (H. Alici).

Peer review under responsibility of The Society of Cardiovascular Academy.
}

were no pathologic findings in his physical examination. Arterial blood pressure was $120 / 80 \mathrm{mmHg}$ and the heart rate was 95 beats/min. The Electrocardiogram (ECG) showed ST segment elevations in anterior derivations (Fig. 1). The patient was immediately taken to intensive care unit because the hospital did not contain interventional laboratory. $300 \mathrm{mg}$ aspirin, $300 \mathrm{mg}$ clopidogrel and 5000 units intravenous heparin were given as initial treatment. The patient was administered intravenous with $100 \mathrm{mg}$ tissue plasminogen activator in $90 \mathrm{~min}$, concurrently 1000 units/h heparin. Resolution of ST-segment elevation was seen on ECG and patient's chest pain disappeared at the end of fibrinolytic therapy. At the forth minute of admission to hospital, the creatine kinase value was $1527 \mathrm{IU} / \mathrm{l}$ and creatine kinase-MB $187 \mathrm{IU} / \mathrm{l}$. The troponin-T was positive. The other hematologic and biochemical laboratory data was normal. The patient was non-smoker and had no cardiovascular risk factor. The patient was transferred to catheter laboratory to clarify the lesion was atherosclerotic plaque or vasospasm, and coronary angiography revealed normal coronary arteries (Fig. 2). There was not any segmental wall motion anomaly on echocardiogram. The patient was discharged with treatment of $300 \mathrm{mg} /$ day aspirin and $75 \mathrm{mg} /$ day clopidogrel and called to the control after 1 month.

\section{Discussion}

Acute myocardial infarction is commonly caused by coronary atherosclerosis. Most of the patients have cardiovascular risk factors such as, hypertension, diabetes, tobacco use, dyslipidemia, obesity, age, gender and family history. Rarely, intracardiac thrombus can cause myocardial infarction in structural heart disease (prosthetic heart valve, mitral stenosis etc.). In our case, myocardial infarction was recovered by fibrinolytic drug and coronary angiogram did not 


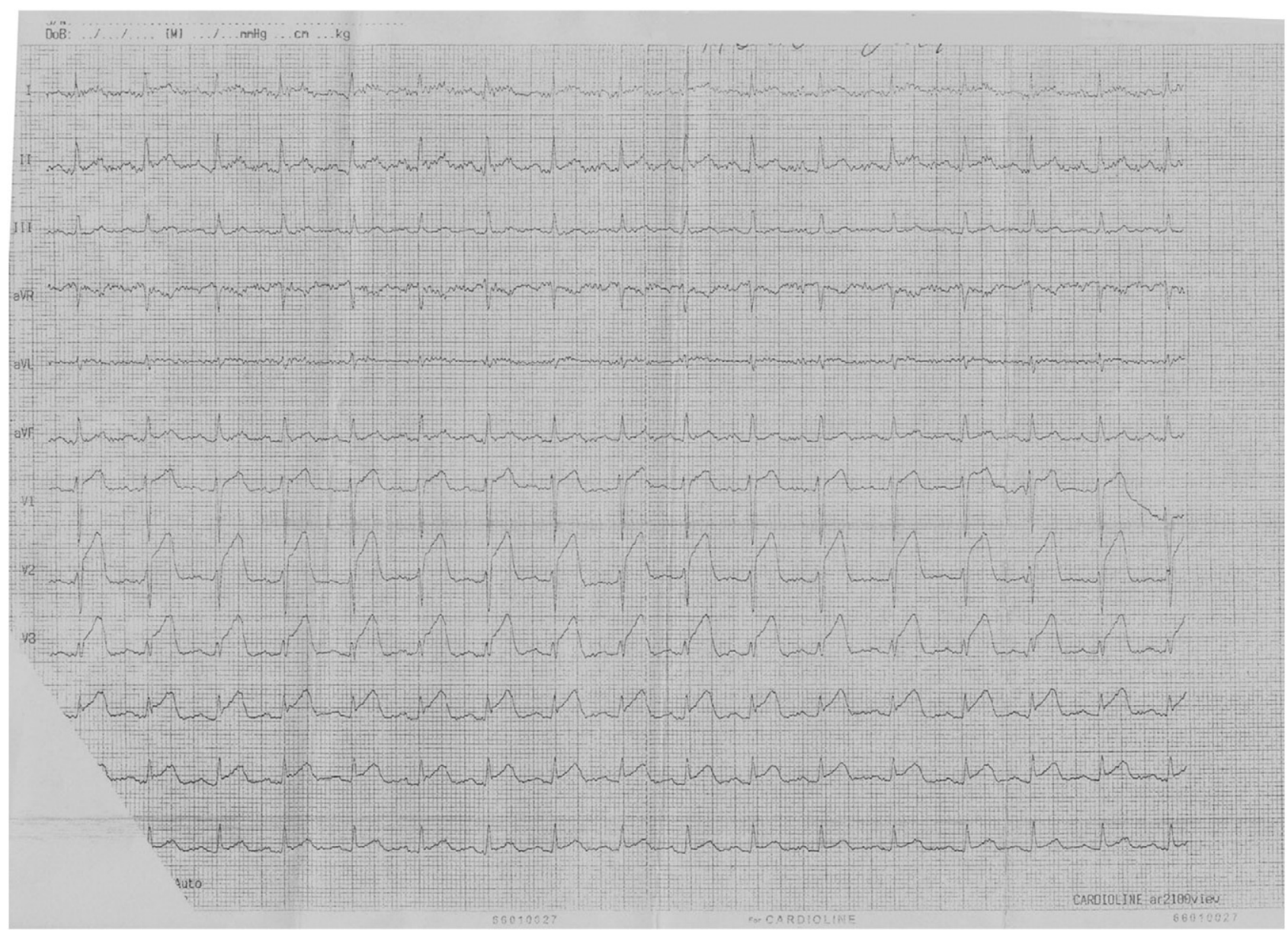

Fig. 1. Electrocardiogram on admission to emergency department. ST segment elevations in anterior derivations.

show any atherosclerotic plaque. In addition, patient did not have any cardiovascular risk factor except gender. The possible mechanism of myocardial infarction in this patient can be hypercoagulation due to the malignancy or chemotherapy regimens.

Venous thrombus in cancer patients is well known, but arterial thrombus is rare and when occurs it can be life-threatening. Cancer cells directly act on thrombin, causing blood coagulation and it is

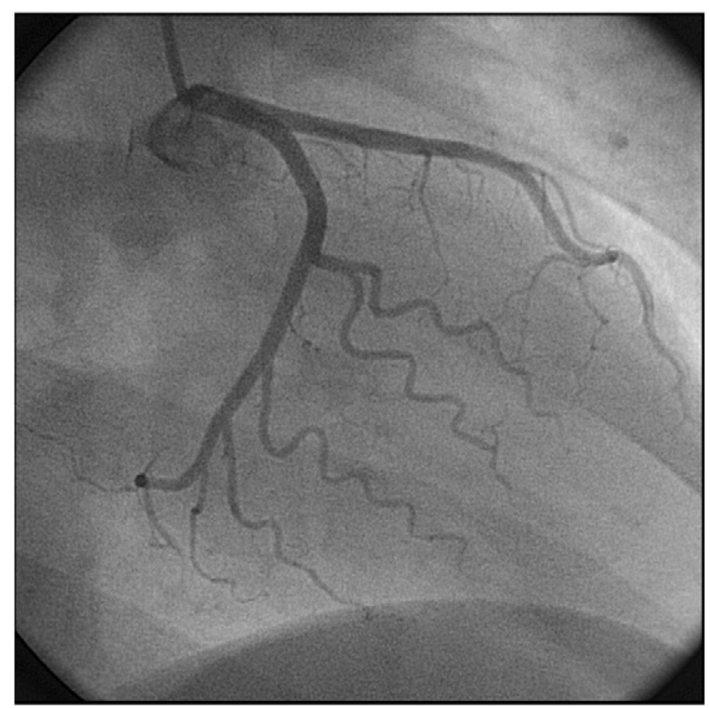

Fig. 2. Normal coronary arteries on coronary angiography. enhanced through interactions between tumor cells and platelets; and the coagulation capacity is enhanced through the enhancement of von Willebrand factor and inflammatory cytokines. ${ }^{3}$ In testicular cancer, tumor presence, high-position orchiectomy, and chemotherapy may cause cardiovascular events, withal, that is associated with a decrease in blood testosterone level. ${ }^{4}$ Many studies showed that myocardial infarction is associated with anticancer drugs in testicular cancer ${ }^{5,6}$ and reports of drug-related myocardial infarction are increased in recent years. ${ }^{7-10}$ Cisplatin is "the usual suspect" of chemotherapy related myocardial infarction in testicular cancer. Shoji et al. reported a review, which shows ten of thirteen patients with myocardial infarction, used cisplatin including combined therapy. ${ }^{10}$ Nephrotoxicity is a considerable side effect of cisplatin, which may induce hypomagnesemia through enhancement of the coagulation capacity and tubular disturbance related to the activation of platelets and vascular endothelial cells, leading to coronary vasospasm. ${ }^{11}$ Hypomagnesemia occurs in $87 \%$ of testicular cancer patients treated with cisplatin. ${ }^{12}$ This may persist for up to years after treatment, so hypomagnesemia caused coronary events may occur in both early terms during chemotherapy and years later. In our patient, magnesium level and coagulation markers were not measured. Bleomycin is related to Raynaud's phenomenon and pulmonary fibrosis and etoposide are thought to the pathogenesis of interstitial pneumonia. Coronary vasospasm is another possible mechanism for chemotherapy related MI, but BEP drugs are not usually responsible for it. 5-fluorouracil is the most common agent associated with coronary artery spasm.

YST is rare in young adults and there was not any literature data about the togetherness of YST and chemotherapy related myocardial infarction. Therewithal, that was the first reported case which was treated with fibrinolytic therapy. Normal coronary arteries and no plaque at 
angiography after successfully fibrinolytic therapy suggest the hypercoagulation of possible mechanism of myocardial infarction in our patient.

Although acute coronary events time varies in testicular cancer, they approximately occur ten days after start of each chemotherapy course. ${ }^{13}$ The earliest literature report about myocardial infarction in testicular cancer was at the fifth day of start of treatment with bleomycin, vinblastine and cisplatin. ${ }^{14}$ Myocardial infarction developed on the fourth day of the third chemotherapy course in our case. In a study with 48 patients, all of the three patients died from myocardial infarction had a history of chest radiation therapy, so late myocardial infarction in testicular cancer is concerned with radiotherapy. ${ }^{15}$

Today, the relationship between cisplatin and myocardial infarction is well known. The testicular cancer patients are younger and usually do not have cardiovascular risk factor. Therefore it is difficult to predict the myocardial infarction in these patients. When BEP protocol is planned, physicians need to pay attention to some points. Patients should be screened for cardiovascular disease and risk factors. Because it is a common health problem in young adults, smoking cessation and weight loss in obese patients should be forced. High-risk patients can be performed with cardiac imaging such as exercise ECG and myocardial scintigraphy. Patients should be given training about the symptoms of coronary events. Magnesium level should be measured during chemotherapy with cisplatin. Because the hypercoagulation is the most possible cause of chemotherapy related myocardial infarction, oncologists should consider anticoagulant treatment to the high-risk patients and those with prior cardiovascular disease.

\section{Conflicts of Interest}

None.

\section{References}

1. Vasdev N, Moon A, Thorpe AC. Classification, epidemiology and therapies for testicular germ cell tumours. Int J Dev Biol 2013;57(2-4):133-139.

2. Chaudhary UB, Haldas JR. Long-term complications of chemotherapy for germ cell tumours. Drugs 2003;63:1565-1577.

3. Gordon SG, Mielicki WP. Cancer procoagulant: a factor X activator, tumor marker and growth factor from malignant tissue. Blood Coagul Fibrinolysis 1997;8:73-86.

4. Takizawa A, Miura T, Fujinami K, Osada Y. Two cases of testicular cancer with low human chorionic gonadotropin (hCG) levels after treatment. Acta Urol 2005;51: 479-482.

5. Haugnes HS, Wethal T, Aass N, et al. Cardiovascular risk factors and morbidity in longterm survivors of testicular cancer: a 20-year follow-up study. J Clin Oncol 2010;28:4649-4657.

6. van den Belt-Dusebout AW, Nuver J, de Wit R. Long-term risk of cardiovascular disease in 5-year survivors of testicular cancer. J Clin Oncol 2006;24:467-475.

7. Ozben B, Kurt R, Oflaz H, et al. Acute anterior myocardial infarction after chemotherapy for testicular seminoma in a young patient. Clin Appl Thromb Hemost 2007 Oct;13(4):439-442.

8. Paiva CE, Michelin OC, Okoshi K. Acute coronary syndrome during chemotherapy: report of three cases. Rev Bras Cancerologia 2009;55(1):55-58.

9. Kawano N, Yamaguchi K, Niki T, et al. Two cases of acute myocardial infarction during combined chemotherapy in young patients with testicular cancer. J Cardiol Cases 2013:7(6):e176-e180.

10. Shoji S, Miyakita H, Shima M, Usui Y, Nagata Y, Uchida T, Terachi T. Acute myocardial infarction during combined chemotherapy with bleomycin, etoposide and cisplatin for testicular cancer. Hinyokika Kiyo 2006 Sep;52(9):723-726.

11. Lajer H, Daugaard G. Cisplatin and hypomagnesemia. Cancer Treat Rev 1999;25: 47-58.

12. Vogelzang NJ, Torkelson JL, Kennedy BJ. Hypomagnesemia, renal dysfunction and Raynaud's phenomenon in patients treated with cisplatin, vinblastin and bleomycin. Cancer 1985;56:2765-2770.

13. Vos AH, Splinter TA, van der Heul C. Arterial occlusive events during chemotherapy for germ cell cancer. Neth J Med 2001;59:295-299.

14. Bodensteiner DC. Fatal coronary artery fibrosis after treatment with bleomycin, vinblastine, and cis-platinum. South Med J 1981 Jul;74(7):898-899.

15. Hannun Y, Vugrin D. Long-term survival in patients treated for testicular seminoma. $J$ Surg Oncol 1990;43:177-180. 